\title{
Association NSS-Dialogues
}

\section{Collection «Indisciplines » : dernière parution}

Raconter le paysage de la recherche

Catherine Mougenot

préface de Bernard Chevassus-au-Louis

Quæ/NSS-Dialogues, 2011, 142 p.

C'est à un voyage

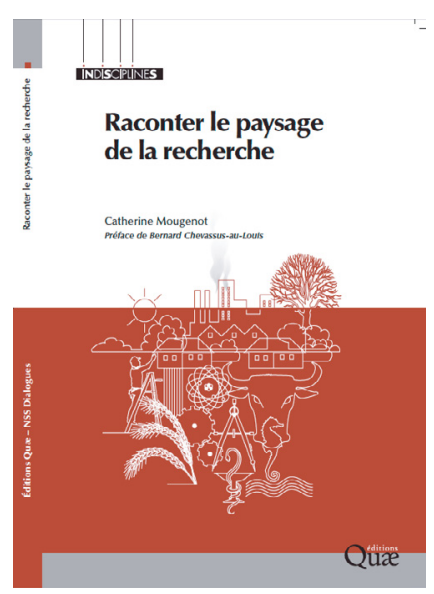

à l'intérieur de la recherche que nous convie Catherine Mougenot, hors des sentiers battus des évaluations, des acquis et des résultats chiffrés. L'aventure commence à l'occasion d'un programme de recherche rassemblant une communauté très large de chercheurs de terrain : écologues, agronomes, sociologues, géographes, économistes, politiciens, anthropologues, juristes, vétérinaires, toxicologues, qui ont tous accepté la confrontation des disciplines et ce qu'elle implique d'atermoiements, de négociations, de renoncements.

Le programme n'est que prétexte à une démarche réflexive dans laquelle l'auteur entraîne les acteurs de la recherche. L'ouvrage prend l'allure de récits où la dimension sensible devient essentielle, ce qui ne veut pas dire que leur travail n'est pas scientifique, mais témoigne de la présence déterminante de cette dimension, au même titre que la passion qui vibre à travers leurs paroles. L'ouvrage devient alors l'histoire des liens de cette communauté, une vision du vécu des chercheurs en regard de quelques grandes questions : la biodiversité, le terrain, l'interdisciplinarité, l'action.

Tout au long de cette collecte de récits, C. Mougenot s'est efforcée en intervenant le moins possible de ne pas trahir les acteurs. Son écriture à chaud colle à l'expérience, jusqu'au moment où, du travail de montage de ces « histoires », l'auteur tire une analyse très pointue des propriétés du récit.

Destiné à la communauté scientifique, cet ouvrage s'adresse également à tous ceux qui vivent la passion de la recherche comme une mise en intrigue.

Catherine Mougenot est sociologue et docteur en sciences de l'environnement. Enseignante et chercheuse à l'université de Liège (Belgique), elle travaille sur les pratiques de gestion de la nature, la problématique des espèces envahissantes et les relations homme-animal. Elle est l'auteur de Prendre soin de la nature ordinaire, coédité par l'Inra et la Maison des sciences de l'homme en 2003.

\section{Sommaire}

\section{Préface}

\section{Sommes-nous réflexifs?}

Des histoires dans une trajectoire Une animation scientifique ouverte Une seconde pression à froid. . . Références bibliographiques

\section{La force du récit}

Raconter la recherche

Accountability : rendre compte

Références bibliographiques

\section{Biodiversité}

Et si la biodiversité était une découverte liée à l'enfance?

Et si la biodiversité était une Histoire?

Et si la biodiversité était une rencontre?

Et si la biodiversité était un objet?

Et si la biodiversité était une action?

Façons de parler de la biodiversité

Références bibliographiques 


\section{Terrain}

Le terrain, un format pour la pensée et un lien sensible Le terrain de relations sociales à part entière

Le terrain de relations sociales à part entière (suite)

Le terrain, laboratoire grandeur nature

Le terrain, toute une histoire

Le terrain, scène de liens

Références bibliographiques

\section{Interdisciplinarité}

Communautés

L'agronomie, à la rencontre de l'écologie

et de la sociologie

Formats

Ensembles souples et changeants

$$
\text { «Couples » interdisciplinaires }
$$

\section{Rencontres}

Apprendre entre soi, tout en apprenant aux autres

À la recherche d'une question véritablement « inter » Complexité et simplification

Le «dur» et le « mou » revisités

Références bibliographiques

\section{De la recherche à l'action}

\section{Confrontation}

Retranscription intégrale d'une table ronde qui n'a jamais eu lieu...
Recherche impliquée

Expériences

De la recherche à l'action publique en train de se faire :

les mesures agro-environnementales (MAE)

Lignes intérieures, lignes multiples

Patchwork

Références bibliographiques

Les ficelles du récit

Les récits et leurs familles

« Raconter, c'est déjà expliquer »

Expliquer ou rendre compte

« Raisonner l'avenir»

Raconter, c'est agir et transformer

Les récits et leurs compétences

Ficelle du récit $n^{\circ} 1$ : processus de création

Ficelle du récit $n^{\circ} 2$ : mise en scène d'événements racontables

Ficelle du récit $n^{\circ} 3$ : construction d'associations inédites

Ficelle du récit $n^{\circ} 4$ : construction d'une relation entre le temps raconté et le temps racontant

Ficelle du récit $n^{\circ} 5$ : construction d'une relation entre narrateur et auditeurs

Des récits légers. .

Plaidoyer pour les récits

Références bibliographiques 